\title{
Skills training programmes for significant others may encourage unmotivated drug users to seek treatment
}

Meyers R, Miller W,Smith J, Tonigan S. A randomized trial of two methods for engaging treatment-refusing drug users through concerned significant others.J Consul and Clin Psychol 2002 Oct;70:1182-5.

\section{QUESTION: Can community reinforcement and family training (CRAFT) for concerned significant others encourage drug users to seek treatment?}

Design

Randomised trial with allocation concealment, but no blinding.

\section{Setting}

Albuquerque, New Mexico; timeframe not specified.

\section{Participants}

Participants were 90 concerned significant others of illicit drug users who refused treatment. All were recruited through newspaper advertisements. 88\% women; $49 \%$ Hispanic; $53 \%$ were parents of drug users and $30 \%$ were partners.

\section{Intervention}

Participants received 1 of 3 interventions: (1) CRAFT behaviour change skills training; (2) CRAFT plus group aftercare sessions; (3) Al-Anon and Nar-Anon facilitation therapy. The CRAFT programme involved 12 1-hour sessions of individual skills training in how to persuade a drug user to enter treatment; domestic violence precautions; motivational strategies; communication training, and positive-reinforcement training. The Al-Anon and Nar-Anon facilitation involved manual guided therapy to facilitate entry into a 12-step family programme. Minimum follow up was $96 \%$ at $3,6,9,12$ and 18 months.

\section{Main outcome measures}

The main outcome measure was drug users seeking treatment. Significant others' functioning and relationship status were measured using several scales of psychosocial adjustment, psychological status and physical health.

\section{Main results}

People receiving CRAFT training were more likely to encourage drug users into treatment compared with Al-Anon / Nar-Anon training (CRAFT alone 59\%, CRAFT plus aftercare 77\%, Al-Anon and Nar-Anon $29 \%$ ). There were no significant differences in the functioning of significant others receiving different interventions.

\section{Conclusions}

CRAFT skills training, with or without group aftercare sessions, may help significant others encourage treatment-refusing drug users to seek help.

\section{COMMENTARY}

Both clinicians and researchers have identified a lack of motivation to change as a major stumbling block for reducing substance use and associated consequences. ${ }^{1}$ People who are unwilling to enter addiction treatment are a challenge because they cannot be reached through traditional clinical strategies such as motivation enhancement. Significant others are in the unique position of having access to such people and having a personal interest in directing the substance user toward recovery. In spite of the potentially critical role of significant others in encouraging treatment, relatively little empirical work has examined this population. Although clinicians generally acknowledge the importance of engaging significant others in the treatment process, few systematic interventions have been developed for family members. Currently, available strategies and resources are targeted solely to the significant other or are difficult to implement.

This article represents a major contribution to the addiction treatment field. It reports that "two-thirds of illicit drug [users] can be engaged in treatment despite their initial refusal, by training [significant others] in reinforcement methods." The study has several noteworthy features: (1) Adding an aftercare condition reinforces that ongoing support is critical since treatment engagement occurs over time; (2) The relatively long follow-up period is critical in the context of a process that occurs over time; (3) The authors recognise that studies of alcohol users do not automatically apply to illicit drug using populations; (4) The use of a random design lends internal validity to the empirical findings. The study uses a relatively small sample. Large-scale replication would strengthen the generalisability of findings. Nevertheless, the results highlight a promising strategy to enhance treatment engagement among difficult-to-reach illicit drug users; (5) The intervention appears relatively inexpensive in the context of the economic and social costs of addiction; (6) An additional strength is that the intervention is manualised, making it easily replicable in other social agencies.

Addiction develops in the context of social relationships. Interventions designed to increase the likelihood of recovery must take the drug user's social context into consideration. A growing body of research suggests that having friends and family who are supportive of abstinence is an important predictor of reduced substance use. ${ }^{23}$ This suggests that drug users who become engaged in the treatment process as a result of significant others may have an increased likelihood of positive outcomes.

Alexandre B Laudet, $\mathrm{PhD}$ National Development and Research Institutes Inc. New York, USA

1 Simpson D, Joe G. Motivation as a predictor of early dropout from drug abuse treatment. Psychotherapy 1993; 30: 357-68. Humphreys K, Moos RJ, Cohen C. Social and community resources and long-term recovery from treated and untreated alcoholism. J Stud Alcoh 1997; 58: 231-8.

3 Humphreys K, Mankowski ES, Moos RJ, Finney JW. Do enhanced friendship networks and active coping mediate the effect of self-help groups on substance abuse? Ann Beh Med 1999; 21: 54-60. 